\title{
Contemporary Staining of Arterial System with Cadaver Fixation: An Experimental Study
}

\author{
Tinción Contemporánea del Sistema Arterial con Fijación Cadavérica: Un Estudio Experimental
}

\author{
"Rostam Ghorbani; **Zahra Tavakol \& *Ali Ghanbari
}

\begin{abstract}
GHORBANI, R.; TAVAKOL, Z. \& GHANBARI, A. Contemporary staining of arterial system with cadaver fixation: An experimental study. Int. J. Morphol., 30(3):1079-1084, 2012.

SUMMARY: Although many methods are investigated, cadavers have unique role for education of gross anatomy. This study was performed to make cadaveric based gross anatomy more enjoyable and decrease the time needed for achievement of arterial system for teachers and learners. The adult rabbits in control $(n=3)$ and experimental groups $(n=9)$ sacrificed following deep anesthesia. The samples were fixed by injection of fixative solution to the left ventricle and the corps dropped to the traditional fixative liquid for at least 1 month. The injected fixative solution of experimental group contained stained human red blood cells. The red blood cells stained by eosin ( $0.25 \%$ in saline) for 30 minutes and injected between two injections of fixative. After passing the period of fixation, the samples were dissected and arterial system in the Neck, Trunk and extremities were recognized. The degree of staining of the arteries categorized as low, medium and high. The data of staining of arteries were analyzed by chi square using SPSS 16.0 for Windows XP (SPSS Inc., Chicago, IL). $\mathrm{P}$ value 0.05 was considered significant. In almost all of the experimental samples, axillary and femoral arteries were stained $(\mathrm{P}=0.005)$. The arteries of the neck (carotids), the wall of thorax (Intercostals), arch of aorta, abdominal arteries (renal, mesenteric) and iliac arteries stained $(\mathrm{p}=0.000)$. This study presents inexpensive and readily used protocol for making easier learning and teaching of gross anatomy by differentiating arteries from their associated nerves and veins in cadavers.
\end{abstract}

KEY WORDS: Artery; Cadaver; Eosin; Packed cells; Staining.

\section{INTRODUCTION}

Gross anatomy has fundamental roles in medicine and is directly related to all clinical branch of this science. Many methods such as traditional lectures, group discussion, self-learning, problem based learning, mind maps and also distance learning are included with teaching and learning of gross anatomy (Korf et al., 2008; Arroyo-Jimenez et al., 2005; Limpach et al., 2008; Yiou \& Goodenough, 2006; Ghanbari et al., 2010). The instruments of these methods are PowerPoint slides, plastic mod-els, radiological images, laparoscopic views of the living body, interactive multimedia packages and cadavers (Collins, 2008).

Cadavers provide learning skills by visual and tactile experiences and also synchronize both halves of the brain by drawing diagrams that leads to integrate science and art. The importance of coordination of both halves of the brain is based on the fact that the medicine is not only a factual science but it can be considered as art in many ways (Stewart $\&$ Charon, 2002). Dissection of cadavers has many applied benefits for the learners. It verifies learning concepts, make trust among the observations of learners, and appreciate the concept of variability and also can be considered as independent thinking method (Pawlina \& Lachman, 2004).

The effectiveness of dissection for teaching and learning anatomy is not completely agreed elsewhere and some medical school presents anatomy without dissection (McLachlan, 2004).

Furthermore, development of computer programs presented a new method besides dissection. But a study was performed to compare 3D computer program with cadaveric studding. This study showed the importance of 3D computer program but the researchers emphasizes that instruments such as computer program or lecture can only use as supplemental tools of learning anatomy and not be replacement for cadavers (Biasutto et al., 2006). This issue confirmed by the other researchers that explained that there

\footnotetext{
* Fertility and Infertility Research Center, Kermanshah University of Medical Sciences, Kermanshah, Iran.

** Student Research Committee, Kermanshah University of Medical Sciences, Kermanshah, Iran.
} 
is no substitute for dissection (Ashraf-Aziz et al., 2002). Finally, a review study concluded that because of existence of bias in the studies that shows computer based learning of anatomy, learning of anatomy by dissection can be considered more effective (Winkelmann, 2007).

However, there are some limitations for using cadavers such as anxiety induced by observing cadavers, the smell of fixation solution, and technical difficulties that decline student attitudes toward cadaveric dissection (Quince et al., 2011; Wei et al., 2007; Ropars et al., 2011). On the other hand, the time devoted to anatomical dissection is declining and in parallel increasing lack of anatomical knowledge induces crisis in surgery that cause damage to underlying structures by surgeons specially during general and vascular surgery (Dobson, 2007; Gartner, 2003; Goodwin, 2000; Raftery, 2006). Finally, fixation materials such as formalin and phenol make the nerves and the veins to be similar staining feature like arteries that leads the difficulties to distinguish these three anatomical structures.

The present study was aimed at investigating a method to stain arterial system simultaneous with fixation of cadavers to leads arteries be more distinguishable from the nerves and the veins during dissection to improve dissection and also learning and teaching of cadaveric based gross anatomy education.

\section{MATERIAL AND METHOD}

Twelve adult rabbits of local strain purchased from local market and were maintained in the animal house at Kermanshah University of Medical Sciences. All animals received care as recommended by the research committee of the University. The rabbits were kept on a regular diet and water at a 12:12 h L: D cycle without any stressful stimuli at $25^{\circ} \pm 2^{\circ} \mathrm{C}$. Experiments were started after one week adaptation. The rabbits divided into two control $(n=3)$ and experimental $(n=9)$ groups. Control rabbits received traditional fixation solution and experimental corps fixed with traditional fixation solution contained stained red cells.

Preparation of staining and fixation solutions. The red blood cells were obtained from Imam Reza Hospital of Kermanshah University of Medical sciences. The cells were washed triplicate with normal saline (Nacl 0.09\%) followed by centrifugation (2000-2500 rpm, 5-10min) and then stained with 3 volume to cell of $0.25 \%$ Eosin (Merck) in saline for 30 minutes. The cells were washed in triplicate with Eosin that each washing step followed by centrifugation (2000$2500 \mathrm{rpm}, 5-10 \mathrm{~min})$. Each $100 \mathrm{cc}$ of traditional fixation solution was made by mixing $20 \mathrm{cc}$ of ethanol (96\%), glycerin $(10 \mathrm{cc})$, formalin $(10 \mathrm{cc})$, phenol (4 gram) and normal saline $(54 \mathrm{cc})$.

Injection of solutions to rabbits. The rabbits were scarified with chloroform and following exposing the thorax, the blood of corps brought out from left ventricle by a needle (number 22). Then we pierced an opening in the right atrium to extract the reminder of the blood by injecting $150 \mathrm{cc}$ of normal saline to the left ventricle and the released blood of right atrium gathered in a jar. To inject the solutions, at first the opening of right atrium was blinded and then the solutions were injected to the left ventricle. In experimental group, the solutions were $150 \mathrm{cc}$ of normal saline that was followed by $150 \mathrm{cc}$ of traditional fixative and then $150 \mathrm{cc}$ of stained red blood cells. In control group, the injected solution was only $150 \mathrm{cc}$ of saline and $150 \mathrm{cc}$ of traditional fixative. Then the corps was left in containers filled with traditional fixation solution for at least 1 month.

Dissection procedure. Dissections were performed on corps of the rabbits at least one month after fixation. The skin of the neck was removed medial to sternoclidomastoid muscle to find carotid arteries (Internal, external and common carotids). The dissection followed up to the margin of mandible and down to clavicle. The skin of the Upper and Lower Limbs was removed in the middle of the limbs towards wrist and ankle joints to dissect Brachial and Femoral arteries in upper and lower limbs separately. The arteries of the trunk could be visible by mild dissection. Aortic arch and its three branches (Brachiocephalic, Left common carotid and left subclavian arteries) and Intercostal arteries dissected in the thorax. Renal, superior mesenteric and inferior mesenteric arteries and also iliac arteries were dissected in abdomen and pelvis.

Statistical analysis. The degree of staining of each artery was categorized as well, moderate and no stained. Statistical analysis was performed by chi square using SPSS 16.0 for Windows XP (SPSS Inc., Chicago, IL). P value $<0.05$ was considered significant.

\section{RESULTS}

Only one experimental sample showed low degree of staining in intercostals and carotid arteries. Another sample was showed medium staining characteristic for carotids but the intercostals arteries were stained well. These data indicated that the staining procedure of the present study is workable for arterial system of the neck and thorax (Table I). The dissected arteries in the neck and thorax revealed 
Table I. The degree of staining of arterial system of rabbits. The corps were fixed by traditional fixation mixture or by stained red cells with eosin (See M\& M).

\begin{tabular}{cl}
\hline $\boldsymbol{P}$ - value & Artery \\
\hline $\mathbf{0 . 0 0 1}$ & Carotid \\
$\mathbf{0 . 0 0 0}$ & Arch of aorta \\
$\mathbf{0 . 0 0 1}$ & Intercostal \\
$\mathbf{0 . 0 0 5}$ & Axillary \\
$\mathbf{0 . 0 0 0}$ & Renal \\
$\mathbf{0 . 0 0 0}$ & Mesenteric \\
$\mathbf{0 . 0 0 0}$ & Iliac \\
$\mathbf{0 . 0 0 5}$ & Femoral \\
\hline
\end{tabular}

that all the branches of aortic arch and also intercostalsarteries were stained very well they were completely differentiated from their associated nerves and veins (Fig. 1.A- D). Moreover, the phrenic and vagus nerves and also jugular veins and in the intercostals spaces, intercostals veins and nerves would be easily distinguishable. All mesenteric and renal arteries of the experimental samples were stained well (Table I) and these arteries would be well identified from neighbouring structures (Fig. 2.A-D). In the limbs, axillary and femoral arteries of 4 experimental were medium stained. However, iliac arteries of all experimental samples stained well (Table I). The separation of arteries of limbs from their related nerves and veins were shown in Figs. 1A-B and 2 A-D.
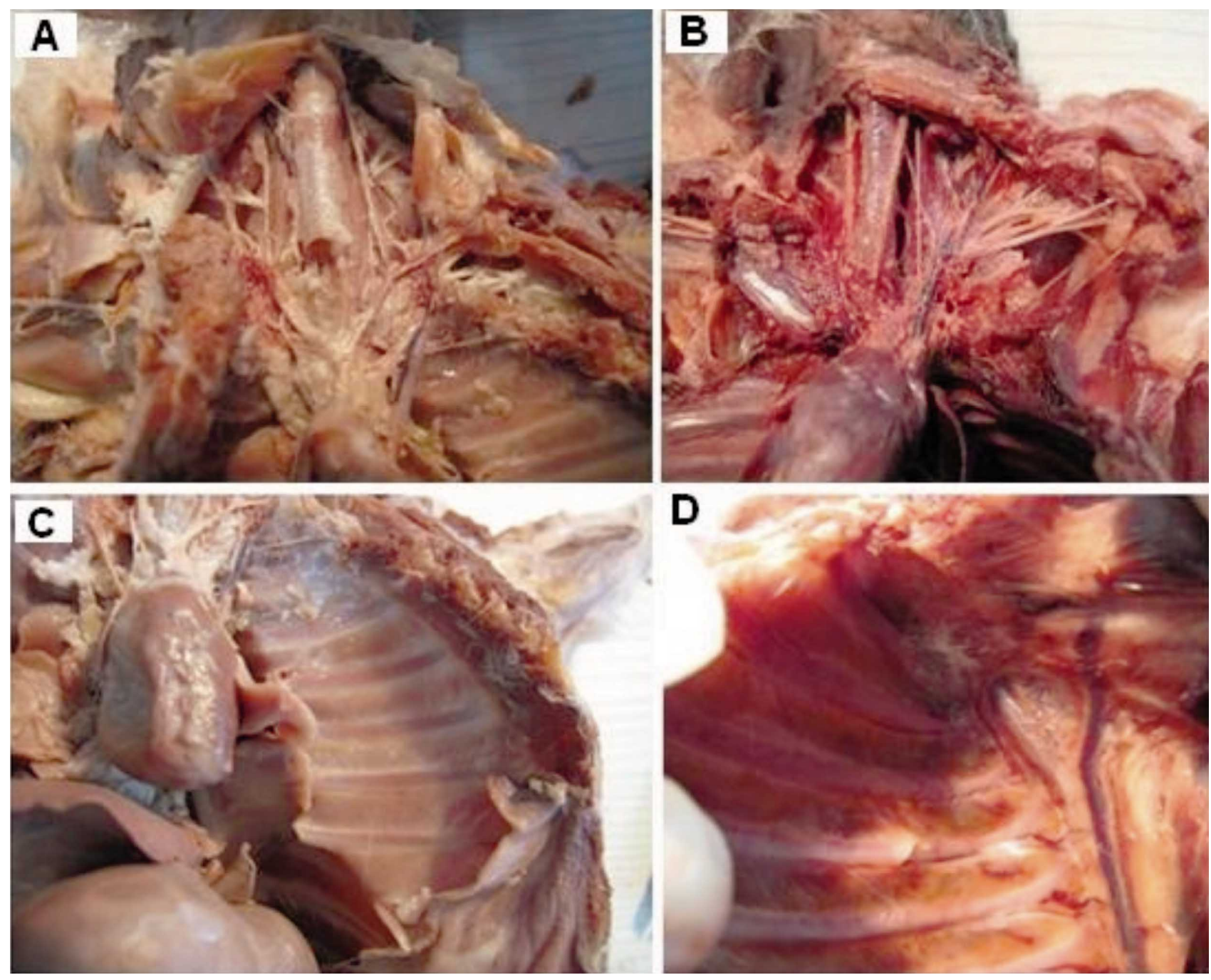

Fig. 1. Photograph showing dissected arteries of the thorax, neck and upper limb of the rabits. The corps were fixed by traditional fixation mixture (lefts) or by stained red cells with eosin (Rights) (See M\& M). A, B: The arch of aorta with the branches; Brachiocephalic, Left common carotid and Left subclavian. The dissection followes the course of carotids in the neck. Internal jugulars ar shown in the neck. C, D: The intercostal arterie. See the staining of azygus vein in right picture in contrast with neighbouring intercostal arteries (D). 

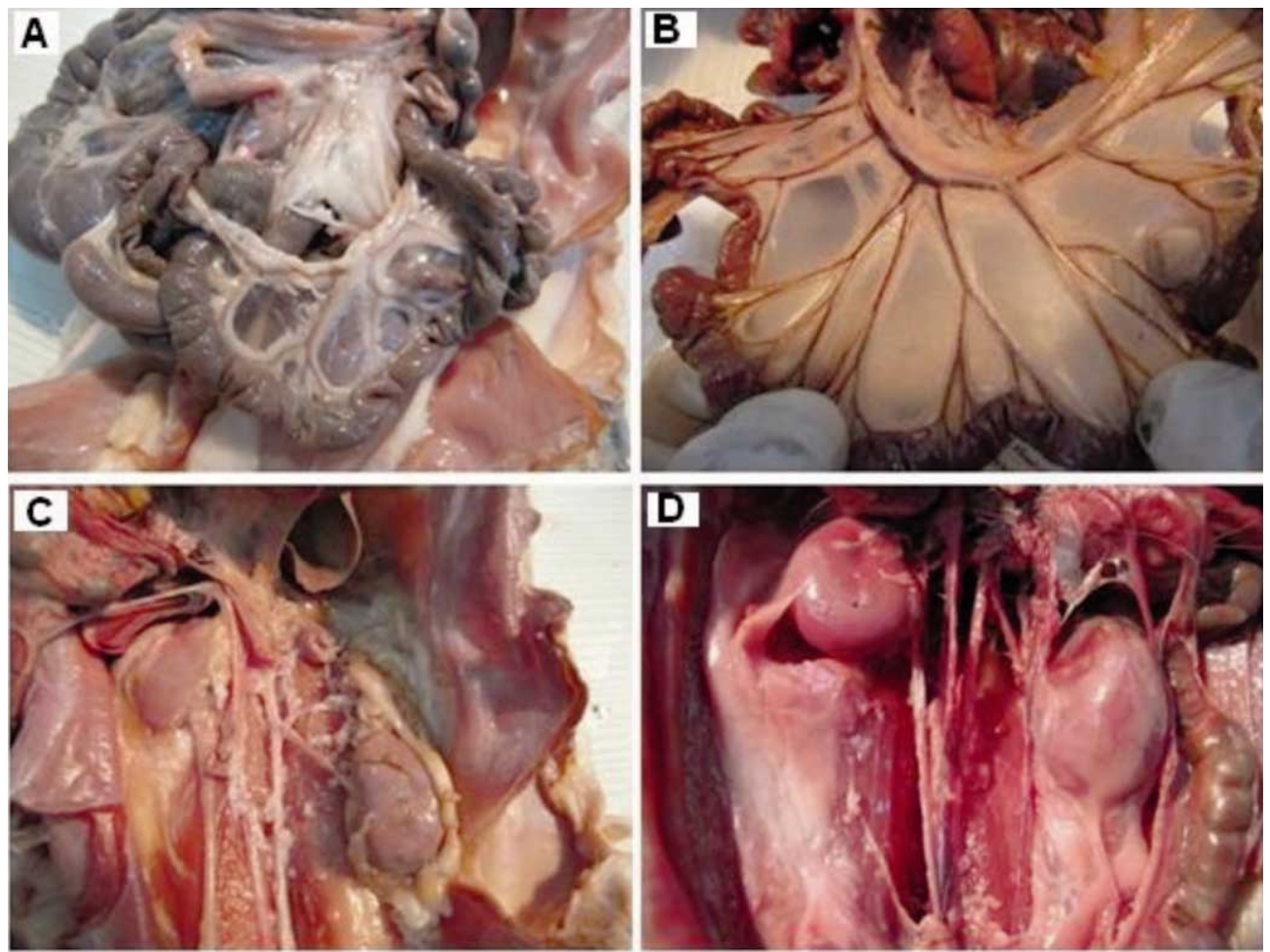

Fig. 2. Photograph showing dissected arteries of the abdomen of the rabits. The corps were fixed by traditional fixation mixture (lefts) or by stained red cells with eosin (Rights) (See M\& M). A, B: The mesenteric arteries. C, D: The renal artery.
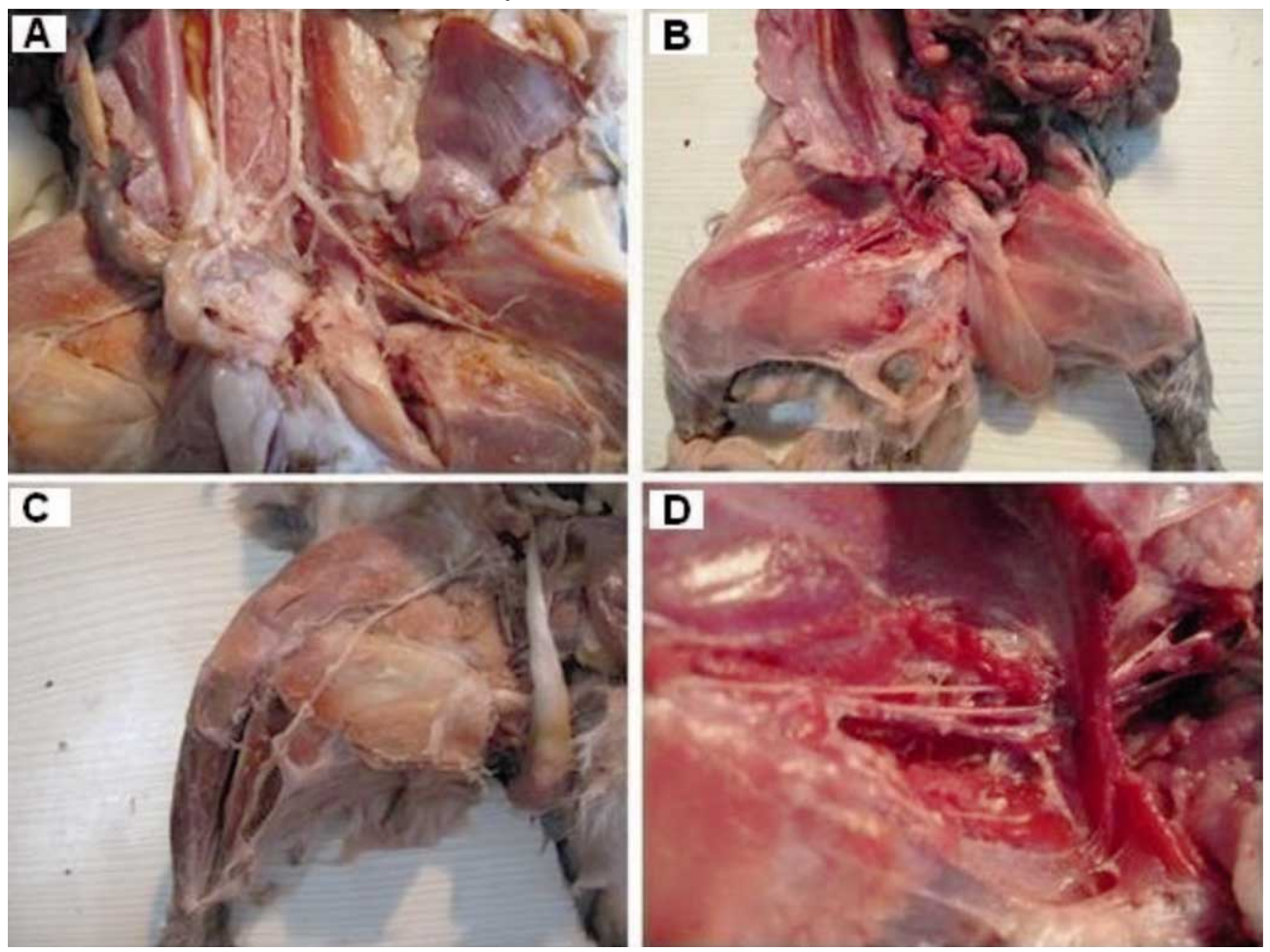

Fig. 3. Photograph showing dissected arteries of the lower limb of rabbits. The corps were fixed by traditional fixation mixture (lefts) or by stained red cells with eosin (Rights) (See M\& M). A, B: The eiliac arteries . C, D: The femoral arteries. See the femoral nerve, vein and artey in experimental group and also external iliac vein and artery (D). 


\section{DISCUSSION}

The study presents inexpensive and readily used protocol for making easier learning and teaching of gross anatomy by differentiating arteries from their associated nerves and veins in cadavers. Up to now, several techniques such as the application of different staining solutions and colored latex have been used to stain and demonstrate the arteries (Pavkov et al., 2004; Pinar et al., 2005; Tubbs et al., 2002) that revealed the details of the anatomy of the region. In details, Tubbs et al. (2002) injected red and blue latex into the arteries and veins of twelve human cadavers ( 8 males and 4 females) found the primary arterial supply to the sympathetic chain and ganglia were from superior to inferior the ascending pharyngeal, ascending cervical, thyrocervical trunk, and supreme intercostals arteries. They also showed that primary venous drainage of these structures were mainly through the direct posterior branches into the internal jugular vein. They concluded that their data should be useful to the surgeon who operates in the cervical region so as to avoid potential complications from disruption of the primary blood supply of the cervical sympathetic chain and ganglia.

Pavkov et al. injected epoxy resin into the vein and artery of internal iliac in six cadavers to describe the anatomy of the uteroovarian anastomosis. They demonstrated that the uteroovarian arcade is an important vein with a caliber similar to that of the ovarian and uterine veins, that there is an impressive network of venous anastomoses between the left and right parametrium and that the fallopian tubes were drained by three separate veins: internal, median, and external tubal veins.

Pinar et al. studied the vascular anatomy of the perioral region in 25 cadaver dissections. Fixation was carried out with $10 \%$ formaldehyde solution followed by injection of Red latex into the common carotid arteries before dissection. Pinar et al. revealed that the labiomental arteries, which formed anastomoses between the FA, inferior labial artery (ILA), and submental artery, showed variations in their course in the labiomental region. Ndiaye et al. (2004) used Congo red to demonstrate the superficial temporal artery (STA) of this study, the detail in the black population. These studies were based on injection of for staining of arterial system. Although, the mixture of the dye with resin or latex does not pass through the arteries but this method could be carried out only for a limited anatomical region because these materials being cold very soon. To access to the all arterial branches, other protocols were carried out by mixture of gelatin and Plumb oxide. But this method had two limitations; the high cytotxicity of Plumb oxide and the other one was that the corps must be freeze all the time and also during dissection (Heymans et al., 2004). However, the Plumb oxide was yellow and separation of the arteries from superficial fascia was difficult. The present study showed the influence of the dye in high distances of arterial three that improve the limitation of resin and latex. Furthermore, no extra cytotoxic reagent was added to toxic traditional fixative mixture and the corps maintained in room temperature of dissection room that was the limitations of Plumb oxide. On the other hand, the arteries stained in red color that would be distinguished easily from superficial fascia that was the minor limitation of Plumb oxide.

In present study we used eosin stained red blood cells as the source of dye. In the literature, only one study was found that used red blood cells as the source of dye. In that study, Makvandi \& Javadnia (2006) injected Safranin stained red blood cells to the internal iliac of a cadaver. The limitations of the work was low sample size (One sample), the injection of dye was performed after passing fixation period and only a region of the body (the branches of internal iliac artery). However, the stained arteries showed the red blood cells would be used as the source of dye that does not pass through the fixed arteries.

All arterial system were stained by the dye that showed the efficacy of the stained red cells to not to pass through the arteries. However, neighboring structures such as fasciae and muscles also stained and the extremities showed lower colored arteries in compare with the trunk and neck. To dissolve these two problems we used saline before injection of the dye and fixative and overcame the lower influence of dye to the extremities but the presence of dye in neighboring structure was likewise exist. Herein we suggest for thinking a method for omitting the reminder of eosin from fixative mixture and another suggestion is injection of stained red cells to the arterial tree in the mid period of time of fixation.

In conclusion, the effectiveness of this method is that the staining is simultaneous with fixation procedure and almost all primary and secondary arteries of total body of a corps would be stained in traditional dissection rooms.

ACKNOWLEDGEMENT. Thanks are due to Kermanshah University of Medical Sciences for financial assistance by a research grant (no. 9083) and to the staff of Department of Anatomy for all their cooperation.

GHORBANI, R.; TAVAKOL, Z. \& GHANBARI, A. Tinción contemporánea del sistema arterial con fijación cadavérica: Un estudio experimental. Int. J. Morphol., 30(3):1079-1084, 2012.

RESUMEN: Aunque muchos métodos de enseñanaza se han investigado, los cadáveres tienen un papel único para la enseñanza de anatomía macroscópica. Este estudio se realizó para hacer de la anatomía basada en el cadáver más agradable y reducir el tiempo necesario para el aprendizaje del sistema arterial de profesores y alumnos. Dos grupos de conejos adultos, uno control $(n=3)$ y otro experimental $(n=9)$ fueron sacrificados después de una anestesia profunda. Las muestras fueron fijadas mediante la inyección de solución en el ventrículo izquierdo manteniéndose los cuer- 
pos en líquido fijador durante al menos 1 mes. La solución fijadorea inyectada en el grupo experimental contenía glóbulos rojos (GR)humanos teñidos. Los GR se tiñeron con eosina ( $0,25 \%$ en solución salina) durante 30 minutos y se inyectaron entre dos inyecciones de fijador. Después del período de fijación, las muestras fueron disecadas, y se reconoció el sistema arterial en el cuello, tronco y miembros. El grado de tinción de las arterias fue clasificado como bajo, medio y alto. Fue utilizado el test de Chi cuadrado con el programa SPSS 16.0 para Windows XP (SPSS Inc., Chicago, IL). Un valor P < de 0,05 fue considerado significativo. En casi la totalidad de las muestras experimentales, se tiñeron las arterias axilar y femoral $(\mathrm{P}=0,005)$. Se tiñeron las arterias del cuello (carótidas), de la pared del tórax (intercostales), arco aórtico, arterias abdominales (renal y mesentérica) y arterias ilíacas $(p=0,000)$. Este estudio presenta un protocolo realizable de bajo costo que permite hacer más fácil el aprendizaje y la enseñanza de la anatomía macroscópica, permitiendo diferenciar las arterias de los nervios y venas asociadas.

PALABRAS CLAVE: Arteria; Cadaver; Eosina; Concentrado de eritrocitos; Tinción.

\section{REFERENCES}

Arroyo-Jimenez, M.; Marcos, P.; Martinez-Marcos, A.; Artacho-Pérula, E.; Blaizot, X.; Muñoz, M.; Alfonso-Roca, M. T. \& Insausti, R. Gross anatomy dissections and self-directed learning in medicine. Clin. Anat., 18(5): 385-91, 2005.

Ashraf-Aziz, M.; Mckenzie, J. C.; Wilson, J. S.; Cowie, R. J.; Ayeni, S. A. \& Dunn, B. K. The human cadaver in the age of biomedical informatics. Anat. Rec., 269(1):20-32, 2002.

Biasutto, S. N.; Caussa, L. I. \& Criado del Río, L. E. Teaching anatomy: cadavers vs. computers? Ann. Anat., 188(2):187-90, 2006.

Collins, J. P. Modern approaches to teaching and learning anatomy. BMJ, 337:a1310, 2008.

Dobson, R. Anatomy teaching in United Kingdom is in crisis, new report says. BMJ, 334(7583):12-12-b, 2007.

Gartner, L. P. Anatomical sciences in the allopathic medical school curriculum in the United States between 1967 and 2001. Clin. Anat., 16(5):434-9, 2003

Ghanbari, A.; Javadnia, F. \& Abdolahi, M. Teaching of gross anatomy for students of medicine by mind map-based power point slides. Med. Teach., 32(3):272, 2010

Goodwin, H. Litigation and surgical practice in the UK. Br. J. Surg., 87(8):977-9, 2000

Heymans, O. Y.; Nélissen, X. P.; Peters, S.; Lemaire, V. \& Carlier, A. New approach to vascular injection in fresh cadaver dissection. $J$. Recostr. Microsurg., 20(4):311-5, 2004.

Korf, H. W.; Wicht, H.; Snipes, R. L.; Timmermans, J. P.; Paulsen, F.; Rune, G. \& Baumgart-Vogt, E. The dissection course - necessary and indispensable for teaching anatomy to medical students. Ann. Anat., 190(1):16-22, 2008.

Limpach, A. L.; Bazrafshan, P.; Turner, P. D. \& Monaghan, M. S. Effectiveness of human anatomy education for pharmacy students via the Internet. Am. J. Pharm. Educ., 72(6):145, 2008.
Makvandi, M. \& Javadnia, F. Application of stained blood cells for the differentiation of arteries and nerves in cadavers. Eur. J. Anat., 10(3):97-100, 2006.

McLachlan, J. C. New path for teaching anatomy: living anatomy and medical imaging versus dissection. Anat. Rec. B New Anat., 281(1):4$5,2004$.

Ndiaye, A.; Toure, S.; Diop, F. M.; Ndiaye, A. S.; Diallo, B. K. \& Sow, M. L. The superficial temporal artery: anatomical type and clinical application to the flap of the fascia temporal superficialis. Morphologie, 88(282):155-9, 2004.

Pavkov, M. L.; Koebke, J.; Notermans, H. P \& Brokelmann, J. Quantitative of the utero-ovarian venous pattern in the adult human cadaver with plastination. World J. Surg., 28(2):201-5, 2004.

Pawlina, W. \& Lachman, N. Dissection in learning and teaching gross anatomy: rebuttal to McLachlan. Anat. Rec. B New Anat., 281(1):911, 2004.

Pinar, Y.A.; Bilge, O. \& Govsa, F. Anatomic study of the blood supply of perioral region. Clin. Anat., 18(5):330-9, 2005.

Quince, T. A.; Barclay, S. I.; Spear, M.; Parker, R. A. \& Wood, D. F. Student attitudes toward cadaveric dissection at a UK medical school. Anat. Sci. Educ., 4(4):200-7, 2011.

Raftery, A. T. Anatomy teaching in the UK. Surgery, 25(1):1-2, 2006.

Ropars, M.; Haegelen, C.; Najihi, N.; Berton, E.; Darnault, P. \& Morandi, $\mathrm{X}$. Analytic study of hopes and perceptions of second-year medical school students during gross anatomy laboratory sessions. Morphologie, 95(309):60-4, 2011.

Stewart, S. \& Charon, R. Art, anatomy, learning, and living. JAMA, 287(9):1182, 2002.

Tubbs, R. S.; Salter, G.; Wellons, J. C. \& Oakes, W. J. Blood supply of the human cervical sympathetic chain and ganglia. Eur. J. Morphol., 40(5):283-8, 2002.

Wei, C. N.; Harada, K.; Ohmori, S.; Wei, Q. J.; Minamoto, K. \& Ueda, A. Subjective symptoms of medical students exposed to formaldehyde during a gross anatomy dissection course. Int. J. Immunopathol. Pharmacol., 20(2 Suppl 2):23-5, 2007.

Winkelmann, A. Anatomical dissection as a teaching method in medical school: a review of the evidence. Med. Educ., 41(1):15-22, 2007.

Yiou, R. \& Goodenough, D. Applying problem-based learning to the teaching of anatomy: the example of Harvard Medical School. Surg. Radiol. Anat., 28(2):189-94, 2006.

Correspondence to:

Ali Ghanbari

Fertility and Infertility Research Center

Kermanshah University of Medical Sciences

Kermanshah, P.O. Box 1568

IRAN

Email: aghanbari@kums.ac.ir

Received: 12-04-2012

Accepted: 22-06-2012 